of the obstacle, and is also diverted in the same direction as the smaller stream. The consequence is that the original stream is diverted from its path as shown, somewhat exaggerated, in fig. 3.

This effect is akin to that obtained from a round-backed blade. The portion of the cylinder or ball which does the diverting of the major portion of the stream is the off side, away from the axis $\mathrm{C}$ (fig. 1). If we cut off a section of this we have a round-backed blade, the action of which on the air is represented in fig. 4. As is well known, this shape of blade gives a decided reaction in the direction towards which the rounded face is pointing, even when the flat side is in direct alignment with the fluid stream impinging on the blade. As the flat side can in this case have no effect upon the fluid, the reaction is due to the diversion of the stream passing along the rounded face, to the contour of which it conforms, the resultant stream taking a line governed by the angle of convergence and relative size of the two streams into which the blade divide

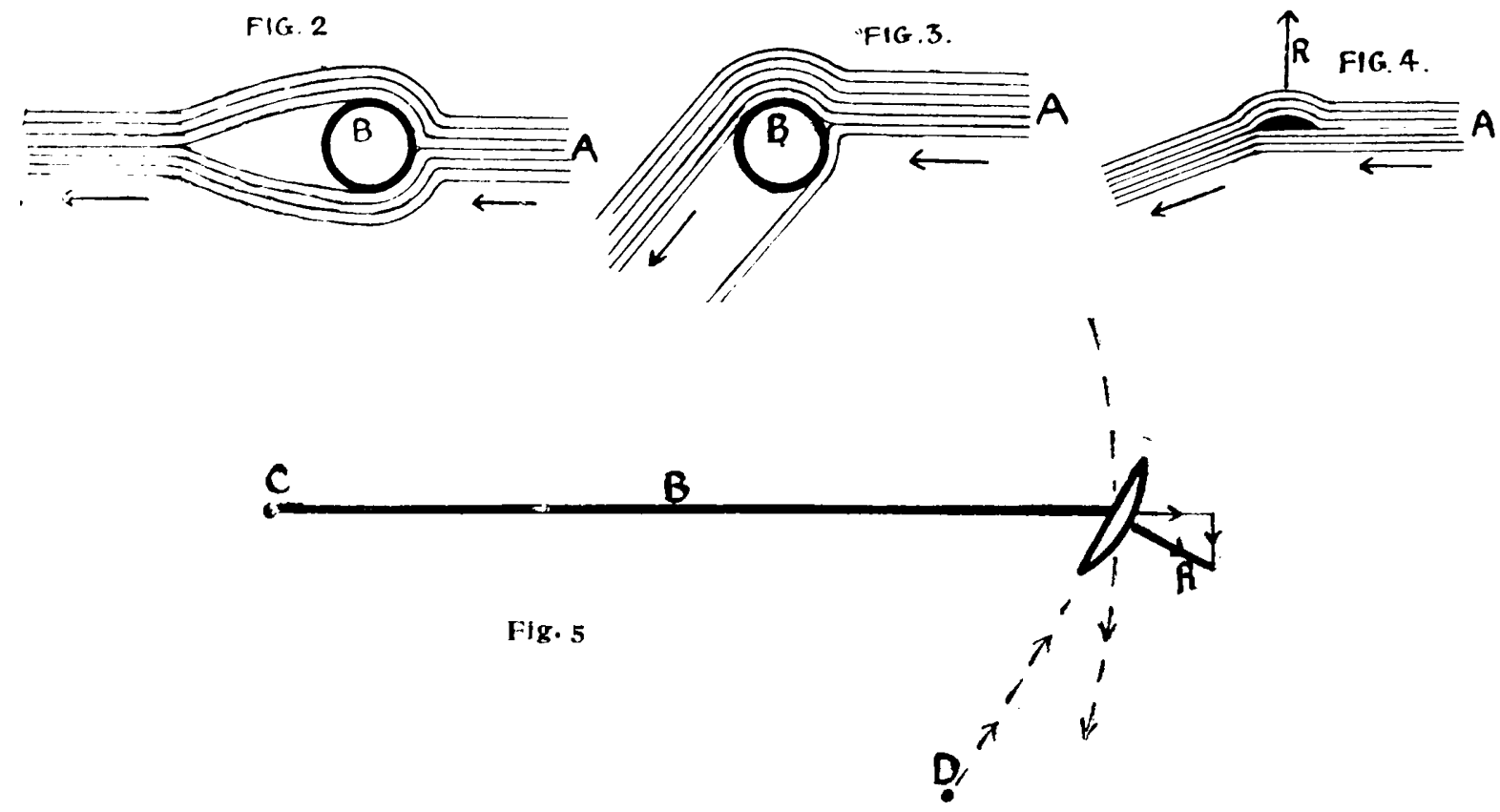

the original stream. The reaction can be represented by a line $R$ at right angles to the flat face (this is approximately correct), and we now have the clue to the behaviour of the ball.

If we were to blow on the ball "off-centre" from a position about axis $\mathrm{C}$ (fig. 1), the reaction $\mathrm{R}$ would obviously be at right angles to the pull of the supporting bar, and the ball would be given a strong impulse round the axis. On the other hand, blowing from a point at right angles to the supporting bar would lead to the reaction $\mathrm{R}$ being balanced by the pull of the bar. We have simply then to move so far towards axis $\mathrm{C}$ as will lead to a portion of reaction $\mathrm{R}$ being $n n$.balanced by the supporting bar to ensure that the ball will come towards us. Fig. 5 (in which a round-backed blade is shown for clearness) shows this condition fulfilled.

April 15, 1910

Bertram G. Cooper

\title{
MAN FLIGHT
}

Sirs,-In answer to your letter, I beg to state that I delivered a lecture lately in the "Verein Deutscher Fliitechnikie" about the further development of aviation.

My conclusions are based on the results of the measurements of the resistance of the air made by my deceased brother and myself, and published in "Der Vogelfiug "(newly published by myself at R. Oldenbourg's Verlag, München). These measurements are exactly uniform with the results of correctly built modern flying machines, which I could prove by mathematical calculation. Regarding this statement, I claim that our further discoveries, published in the same book, are also reliable ; especially I referred to the wonderful increase of the resistance of the air by beating wings, in opposition of the effect of the screw. I proved this by an experiment shown in the lecture hall. This stated a multiplication of the air pressure of seven times more than the general calculation otherwise shows. Based on this fact, I am able to prove that man can fly with his own force without a motor, as only one-third h.p. is required when a wind of at least six metres per second or more is blowing. I stated further that the question of equilibrium has to be solved before it is possible to muke experiments, and that my special attention at present is occupied to construct a combination of special formed wings, which keep the equilibrium in the ever changing wind. 